\title{
STUDIES ON THE INTERACTION OF BARBITURATES WITH REACTIVE OXYGEN RABICALS: IMPLICATIONS REGARDING BARBITURATE PROTECTION AGAINST CEREBRAL ISCHAEMIA
}

\author{
David V. Godin, Mary Jane Mitchell and Brian A. Saunders
}

\begin{abstract}
Although the molecular basis of ischaemic damage of the brain is as yet unknown, it has been postulated that the uncontrolled production of reactive oxygenated species derived from molecular oxygen (including hydroxyl radicals, superoxide radicals and singlet oxygen) may play a major role in the production of such injury. The ability of various barbiturates to modify the nature and extent of membrane damage produced by various oxygen radicals generated under well-defined conditions in vitro has been directly examined using the human erythrocyte as model membrane system. Our results indicate that barbiturates are unlikely to exert their protective effects by directly scavenging singlet oxygen, superoxide or hydroxyl radicals. The highly lipophilic barbiturate thiopentone is capable of decreasing the susceptibility of membranes to oxidative degradation by a direct membrane action, a property shared by amphipathic membrane stabilizers such as propranolol. The barbiturates were found to stabilize the haeme moiety of haemoglobin preventing its conversion to methaemoglobin in the presence of hydrogen peroxide. It is postulated that a major aspect of barbiturate action in decreasing ischaemic injury to the brain may involve the stabilization of haeme-coordinated iron complexes, thereby preventing the participation of these ubiquitous substances in initiating and potentiating free radical-mediated processes which have been implicated in the production of such injury.
\end{abstract}

Key Words: Pharmacology, barbiturates, interaction with reactive oxygen radicals; BRAIN, ischaemic injury, barbiturate protection.

THE ABILITY of barbiturates to offer marked protection of the brain against hypoxic or ischaemic injury in a variety of animal model systems $^{1-4}$ has led to increasing interest in the possible use of iatrogenic barbiturate coma in the clinical management of various cerebral insults. The barbiturates are capable of exerting a number of potentially relevant beneficial actions, including a decrease in elevated intracranial pressure ${ }^{5}$ and odema formation, ${ }^{6}$ a reduction in neuronal metabolic rate and seizure activity ${ }^{7}$ and the maintenance of adequate cerebral blood flow and substrate utilization. ${ }^{8}$ However, recent investigations into the molecular basis of certain central nervous system degenerative lesions have postulated a crucial role of free radicalmediated alterations at the level of subcellular membrane systems. ${ }^{9}$ The high content in brain of phospholipids with unsaturated fatty acids ${ }^{10}$

David V. Godin, Ph.D., Associate Professor; Mary Jane Mitchell, M.D., Research Fellow; Brian A. Saunders, M.D., Assistant Professor; Departments of Pharmacology and Anaesthesia, Faculty of Medicine, The University of British Columbia, 2176 Health Sciences Mall, Vancouver, B.C., Canada V6T 1W5. makes this tissue particularly vulnerable to free radical attack. The radical species initiating cellular injury are believed to be reactive products of molecular oxygen which are formed during univalent oxygen reductive processes accompanying normal cellular metabolism and electron transport. ${ }^{11}$ Uncontrolled production of these species may arise from the abnormal redox cycling of co-factors in ischaemia or hypoxia as a result of the abrupt loss of $\mathrm{O}_{2}$ at the final terminus. ${ }^{9}$ The reactive oxygen species would include hydroxyl radicals ( $\mathrm{HO} \cdot$ ) superoxide radicals $\left(0_{2}^{-}\right)$, singlet oxygen $\left({ }^{\prime} O_{2}\right)$ and hydrogen peroxide $\left(\mathrm{H}_{2} \mathrm{O}_{2}\right)$.

Within this context, then, the protective effects of barbiturates could result from their ability to selectively scavenge one or more of these reactive oxygen species ${ }^{12,13}$ or from alierations at the level of cellular membranes which would either decrease their susceptibility to attack or preserve their structural integrity by a membrane stabilizing action ${ }^{14}$ subsequent to damage. However, direct evidence bearing on the involvement of oxygen radicals in ischaemic injury of the brain or in its amelioration by

Can. Anaesth. Soc. J., vol. 29, no. 3, May 1982 
barbiturates is at present lacking. Although numerous in vivo studies have been described in animals, the inherent complexities of such experiments have allowed little mechanistic information on molecular aspects of barbiturate action to be obtained. The aim of the present investigation, therefore, was to examine in vitro the ability of barbiturates to modify oxidative damage produced in a model membrane system by exposure to various chemically generated oxidizing species which have been implicated in the production of ischaemic/hypoxic cerebral injury in vivo. Our experiments do not support direct free radical trapping as a plausible mechanism of barbiturate protection, but rather suggest that interactions at the level of haemecoordinated iron may be important in determining these protective actions.

\section{METHODS}

\section{Peroxidation Studies}

Blood was obtained by venipuncture from clinically normal volunteers immediately before each experiment, using heparin as anticoagulant. Erythrocytes were washed twice with isotonic saline containing $2 \mathrm{mM}$ sodium azide to inhibit catalase, thereby greatly improving the reproducibility of hydrogen peroxide-induced oxidative damage to red cells. ${ }^{15}$ A 25 per cent suspension of red cells in saline/azide was prepared and $0.5 \mathrm{ml}$ of this suspension was combined with $2.0 \mathrm{ml}$ of a solution of barbiturate (or other drug to be tested) in saline/azide and the mixture was allowed to equilibrate for $5 \mathrm{~min}$ at $37^{\circ} \mathrm{C}$. Peroxidative challenge was initiated by the addition of $2.5 \mathrm{ml}$ of a freshly prepared $\mathrm{H}_{2} \mathrm{O}_{2}$ solution ( $10 \mathrm{mM}$, stored on ice) in saline/azide and containing the same concentration of test drug as in the preincubation. Following a $30 \mathrm{~min}$ incubation at $37^{\circ} \mathrm{C}$, the reaction was terminated by the addition of $2.5 \mathrm{ml}$ of 28 per cent trichloroacetic acid (W/V) containing $0.1 \mathrm{M}$ sodium arsenite, the latter serving to stabilize the chromogen produced by thiobarbituric acid in the determination of malondialdehyde, ${ }^{15} \mathrm{a}$ byproduct of lipid peroxidation, as described below. The mixture was centrifuged and a $4.0 \mathrm{ml}$ aliquot of supernatant was combined with $1 \mathrm{ml}$ of a 0.67 per cent aqueous solution of thiobarbituric acid. Colour development was effected by boiling for 15 minutes and the chromophore was extracted into cyclohexanone. The extent of malondialdehyde (MDA) production was estimated from the absorbance at $532 \mathrm{~nm}$.

\section{Photolytic Generation of Singlet Oxygen}

These studies were performed using erythrocyte membranes prepared by a stepwise hypotonic lysis procedure described previously. ${ }^{16}$ The photolysis medium consisted of $1.5 \mathrm{ml}$ membrane suspension (approximately $3.5 \mathrm{mg}$ protein $/ \mathrm{ml}), 5.0 \mathrm{ml}$ Tris buffer $(0.165 \mathrm{M}, \mathrm{pH}$ 7.4), Rose Bengal (at a final concentration of $10^{-5} \mathrm{M}$ ) and $1.0 \mathrm{ml}$ solution of test drug in distilled water, all in a final volume of $10.0 \mathrm{ml}$. Samples (in $20 \mathrm{ml}$ glass vials) were irradiated for $2 \mathrm{~min}$ at a $5 \mathrm{~cm}$ distance from a Leitz $35 \mathrm{~mm}$ slide projector (Wetzlar, Germany) employed as light source. Following centrifugation and washing with Tris buffer, membranes were resuspended in $1.2 \mathrm{ml}$ of water and suitable aliquots were analyzed for MDA (as outlined above) and for sulfhydryl group content using 5,5'-dithio-bis(2-nitro-benzoic acid) as described by Godin et al. ${ }^{17}$

Xanthine/xanthine Oxidase-dependent Production of Superoxide

This cell-free system consisted of the following components in a total volume of $3.0 \mathrm{ml}$ at the final concentrations indicated: phosphate buffer $(50 \mathrm{mM}, \mathrm{pH} 7.6)$, cytochrome c $(0.05 \mathrm{mM})$, xanthine $(0.15 \mathrm{mM})$, xanthine oxidase $(20 \mu \mathrm{g} /$ $3.0 \mathrm{ml}$ reaction mixture) and barbiturate or radical scavenger to be examined. The formation of superoxide radical could be monitored spectrophotometrically by virtue of its ability to reduce cytochrome $c$ and thereby cause an increase in absorbance at $550 \mathrm{~nm} .^{18}$

\section{Treatment of Insact Erythrocytes with Sodium Nitrite}

The conversion of haemoglobin to methaemoglobin in intact red cells was achieved by treatment with sodium nitrite ${ }^{19}$ as follows. A $1.5 \mathrm{ml}$ aliquot of packed saline-washed red cells was incubated for 15 minutes in an isotonic saline medium containing $1 \mathrm{mg} / \mathrm{ml}$ of sodium nitrite. The final volume was $5.0 \mathrm{ml}$ and the suspension was intermittently vortexed throughout the course of the incubation to ensure complete mixing. The treated cells were then diluted with cold saline and washed five times by centrifugation to remove residual sodium nitrite. A 25 per cent suspension of these modified cells was prepared in saline $-2 \mathrm{mM}$ sodium azide and 
this was used in peroxidation studies as described above.

\section{Spectrophotometric Measurement of Methae- moglobin Formation in Red Cell Haemo- lyzates Exposed to Hydrogen Peroxide}

The effect of barbiturates on the peroxideinduced oxidation of haemoglobin to methaemoglobin was investigated using haemolyzates prepared by treating $0.5 \mathrm{ml}$ packed washed erythrocytes with $50 \mathrm{ml} 2 \mathrm{mM}$ sodium azide for 10 minutes at room temperature, followed by centrifugation. One $\mathrm{ml}$ of the supernatant was combined with $1.0 \mathrm{ml}$ of a solution containing test drug or sodium chloride and $0.2 \mathrm{ml} \mathrm{H}_{2} \mathrm{O}_{2}$ ( 0.03 in $2 \mathrm{mM}$ sodium azide) in a final volume of $3.0 \mathrm{ml}$. The slope of the linear relationship between the absorbance increase at $630 \mathrm{~nm}$ and time obtained from double logarithmic plots of the data was a sensitive index of the effects of various pharmacological agents on the susceptibility of the haeme moiety of haemoglobin to oxidation in the presence of peroxide.

\section{MATERIals}

The following substances were obtained from Sigma: thiobarbituric acid, mannitol, cytochrome $c$, sodium formate, superoxide dismutase, Tris, xanthine, xanthine oxidase and $\mathrm{dl}$ propranolol. Sodium azide, $\mathrm{H}_{2} \mathrm{O}_{2}(30 \%)$, trichloroacetic acid and sodium arsenite were purchased from the Fisher Chemical Company. Rose Bengal was obtained from Aldrich, sodium pentobarbitone and sodium phenobarbitone from BDH Chemicals of Canada and sodium thiopentone from Abbott Laboratories, Montreal.

\section{RESULTS}

\section{Singlet Oxygen}

Irradiation of aerated solutions in the presence of Rose Bengal results in the generation of singlet oxygen, ${ }^{20}$ a highly reactive form of molecular oxygen wherein one of the two unpaired electrons in ground state triplet oxygen undergoes spin inversion. ${ }^{21}$ Singlet oxygen is capable of damaging both the protein and the phospholipid components of membranes, causing a marked reduction in protein sulfhydryl titre and a large increase in levels of malondialdehyde (MDA), a by-product of phospholipid oxidation (Figure 1). The involvement of singlet oxygen in

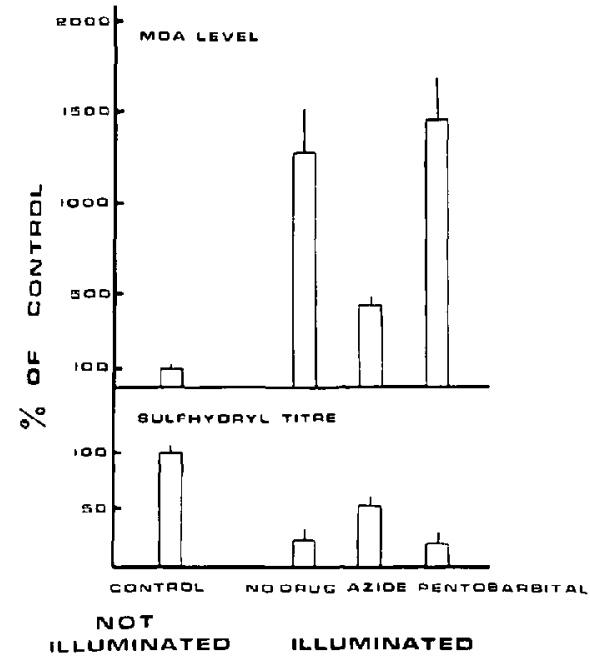

FIGURE 1 Effects of azide $(10 \mathrm{mM})$ and pentobarbitone $(10 \mathrm{mM})$ on Rose Bengal-sensitized photolytic changes in erythrocyte membrane malondialdehyde (MDA) levels and sulfhydryl titres. [Values are expressed as mean \pm S.D.]

these alterations was confirmed by the ameliorating effects of azide, a known singlet oxygen quencher. $^{21}$ In contrast, pentobarbitone and phenobarbitone (not shown) were devoid of protective actions in this system even at concentrations as high as $10 \mathrm{mM}$ (Figure 1).

\section{Superoxide Radical}

Superoxide radicals are produced in vitro during the course of xanthine oxidation by xanthine oxidase and the reduction of cytochrome $\mathrm{c}$ under these conditions provides a convenient means of monitoring the formation of superoxide as a function of time. ${ }^{18}$ This is illustrated in Figure 2 and the marked inhibitory effect of superoxide dismutase (SOD) on the increase in absorbance at $550 \mathrm{~nm}$ associated with cytochrome $c$ reduction clearly implicates superoxide radicals in the process. The lack of effect of pentobarbitone, phenobarbitone or thiopentone (the latter not shown) in this in vitro system indicates that barbiturates are incapable of directly scavenging superoxide radicals.

\section{Hydrogen Peroxide}

The rationale for examining the membrane oxidative damage produced by hydrogen peroxide was two-fold: first, because this potentially damaging species may be produced in vivo by 


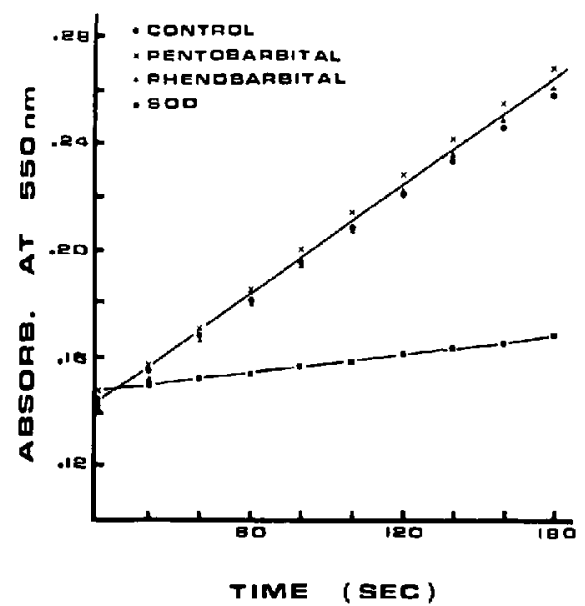

Figure 2 Effects of barbiturates or superoxide dismutase (SOD) on the reduction of cytochrome $c$ by superoxide radical generated by the xanthine oxidasecatalyzed oxidation of xanthine. [The data presented are the results from a single representative experiment. Pentobarbitone and phenobarbitone were tested at a final concentration of $2 \mathrm{mM}$ and SOD at a concentration of $50 \mu \mathrm{g}$ per $3.0 \mathrm{ml}$ reaction mixture.]

many subcellular organelles and it may also arise from the dismutation of superoxide radicals; ${ }^{22}$ secondly, and perhaps more importantly, it may potentially give rise, by decomposition and radical interconversion processes, to a mixture of reactive oxygen derivatives (including superoxide, singlet oxygen and hydroxyl radicals) whose combined presence may give rise to characteristic patterns of cellular injury which may more closely approximate the situation in vivo. ${ }^{23}$ Exposure of intact erythrocytes to $5 \mathrm{mM}$ hydrogen peroxide for $30 \mathrm{~min}$ at $37^{\circ} \mathrm{C}$ was associated with a visible colour change due to methaemoglobin formation and the production of peroxidative damage as reflected by a marked elevation in MDA levels. Treatment of haemoglobin-free erythrocyte membranes under the same conditions failed to produce consistent elevations in MDA levels, suggesting a role of haeme-coordinated iron, a known catalyst of lipid peroxidation, ${ }^{24}$ in peroxide-induced damage to intact erythrocytes. Barbiturates exerted marked protective effects against lipid peroxidative changes in intact cells. The degree of protection was concentration-dependent and was greater for thiopentone and pentobarbitone than for phenobarbitone (Figure 3). No protection was found with azide or superoxide dismutase, although the latter was shown to retain full

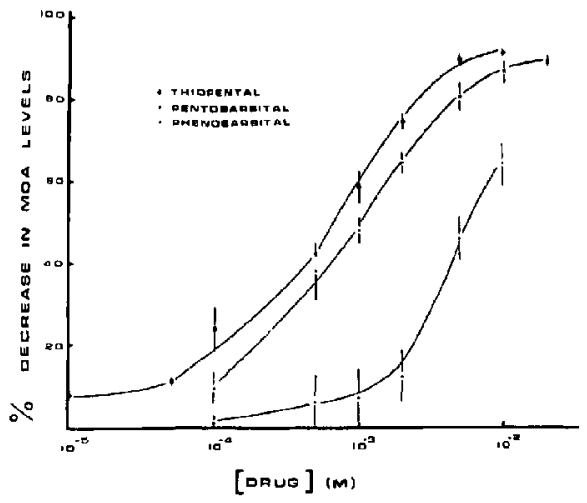

FIGURE 3 Effects of barbiturates on the enhancement of MDA levels in intact erythrocytes exposed to hydrogen peroxide. [Each point represents the mean \pm S.D. of triplicate experiments using six different blood samples.]

activity under the conditions used to produce erythrocyte peroxidation. Specific hydroxyl radical scavengers such as mannitol $(100 \mathrm{mM})$ or sodium formate $(20 \mathrm{mM})$ were found to exhibit a variable, but small, degree of protection which never exceeded 30 per cent. To explore the possibility that barbiturates might act at least in part by the direct scavenging of hydroxyl radicals, we have examined the extent of protection produced by pentobarbitone and of hydroxyl scavengers alone and in combination, with the aim of determining whether or not protective effects are additive. By analogy with the situation described by $W^{2} b^{25}$ for two different inhibitors acting on the same enzymatic process, if the protective actions of a barbiturate and a specific hydroxyl radical scavenger are strictly additive when present simultaneously, the two inhibitors are presumed to act by different mechanisms. ${ }^{25}$ By this criterion, our observation that the protective effects of pentobarbitone and formate on erythrocyte peroxidative damage are strictly additive suggests that barbiturates are not effective scavengers of hydroxyl radicals.

If, as seems likely from our results presented thus far, the barbiturates do not offer protection against membrane peroxidative damage by virtue of their radical scavenging properties, alternative mechanisms must be considered. One possibility was that the barbiturates might decrease the susceptibility of erythrocytes to peroxidation by a direct membrane stabilizing action. ${ }^{14}$ Consistent with this hypothesis was the finding that propranolol, employed here as a prototype lipophilic cation with membrane stabi- 
lizing properties, ${ }^{26}$ effectively protected erythrocytes against lipid peroxidation even at concentrations as low as $10^{-5} \mathrm{M}$ (Figure 4). Unlike the barbiturates, however, protection against MDA formation by propranolol was not associated with a visible reduction in the extent of methaemoglobin formation. These observations suggested that the protection by barbiturates of intact erythrocytes against damage induced by hydrogen peroxide may involve an action at the level of haeme-coordinated iron. This was further substantiated by experiments using erythrocytes pretreated with sodium nitrite to promote the formation of methaemoglobin. ${ }^{19}$ Under these conditions (Figure 5) enhanced production of MDA following peroxide challenge was noted and the protective effects of pentobarbitone were markedly reduced. In contrast, the extent of protection by propranolol was unaffected by nitrite pre-treatment (Figure 5).

Our findings indicate, therefore, that a major component of the protective action of barbiturates is exerted intracellularly, rather than at the membrane level and that this likely relates to the ability of these substances to prevent membrane damage linked to the oxidative conversion of haemoglobin to methaemoglobin. Direct spectrophotometric examination of the influence of barbiturates on the formation of methaemoglobin in membrane-free red cell haemolysates exposed to hydrogen peroxide (Figure 6) confirmed this proposal. The order of potency of the three analogues investigated qualitatively paralleled that for protection of intact erythrocytes-

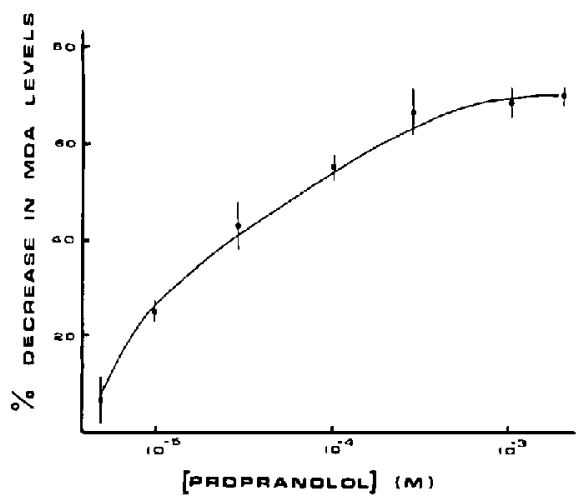

FIGURE 4 Effect of propranolol on the increase in MDA levels of intact erythrocytes exposed to hydrogen peroxide. [Each point represents the mean \pm S.D. of triplicate experiments using six different blood samples.]

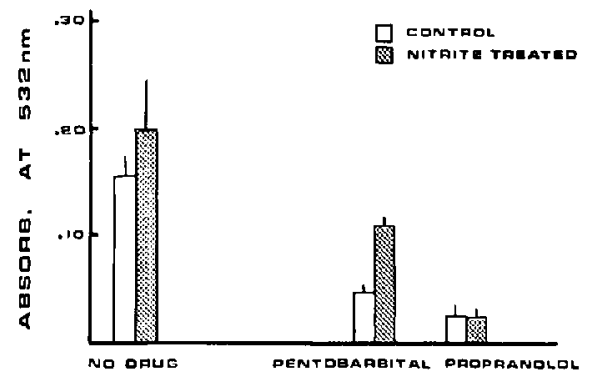

FIGURE 5 Effect of sodium nitrite pretreatment on the protection by pentobarbitone $(2 \mathrm{mM})$ or propranolol $(0.5 \mathrm{mM})$ against peroxidative damage to intact erythrocytes exposed to hydrogen peroxide. [Each value represents the mean \pm S.D. of experiments using six different blood samples.]

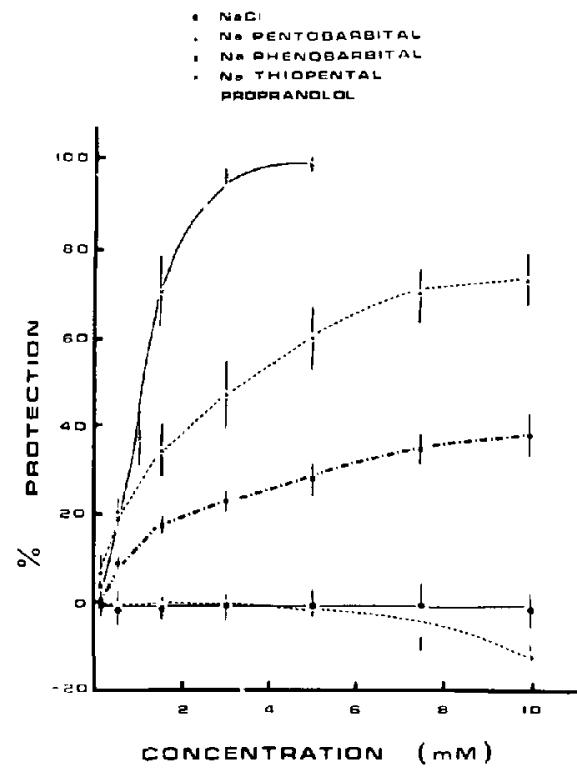

FIGURE 6 Effects of various barbiturates and propranolol on the oxidation of haemoglobin to methaemoglobin by hydrogen peroxide in cell free red cell haemolysates. [Each point represents the mean + S.D. of experiments using a minimum of three different blood samples.]

against peroxidative damage (Figure 3). As expected on the basis of our earlier observations, propranolol exerted no protection against peroxide-induced methaemoglobin production, even at concentrations greatly in excess of those required to produce maximal protection against peroxidative damage to intact cells (Figure 4). 


\section{DISCUSSION}

High dose barbiturate therapy is receiving increasing attention as a pharmacological approach to the management of neurological disorders involving cerebral ischaemia, brain swelling and increased intracranial pressure. ${ }^{27}$ Although some experimental evidence exists in support of this new therapeutic modality, ${ }^{2-4}$ the results of many studies have been inconclusive or conflicting. ${ }^{28-30}$ A number of tentative conclusions may be drawn: first, success in barbiturate protection seems greatest in incomplete regional ischaemia as compared with global ischaemia; ${ }^{31}$ secondly, there are indications that barbiturates may still exert protective effects even when therapy is delayed for some time after the onset of ischaemia; ${ }^{2-4,32}$ and finally, dosage adjustment is critical if potentially beneficial actions are to out-weigh adverse consequences relating to circulatory and respiratory failure. ${ }^{33}$

A number of groups, most notably that of Demopoulos, ${ }^{9}$ have postulated the involvement of oxygen free radicals in various types of degenerative changes in the central nervous system, including spinal cord impact injury, cerebral ischaemia and cold injury. Interestingly, such free radicals have also been implicated in the process of inflammation, ${ }^{34}$ in oxygen toxicity ${ }^{23}$ and in the selective cytotoxicity induced by a number of experimental agents, such as 6-hydroxydopamine, 6,7-dihydroxytryptamine and dialuric acid. ${ }^{35}$ The theory has therefore emerged that the protective actions of the barbiturates against ischaemic injury of the brain may reside, at least in part, in their ability to scavenge reactive oxygen-derived radicals whose uncontrolled production in ischaemia or hypoxia would occur as the result of alterations in normally tightly coupled electron transport chain processes. ${ }^{9}$ Recent experiments described by Smith et al., ${ }^{35}$ however, have shown that although thiopentone offered marked protection of brain phospholipids against peroxidative damage in vitro using an iron-ascorbate system, pentobarbitone and phenobarbitone were inactive. Since these latter two barbiturates have previously been shown to be capable of protecting the brain against ischaemic injury, the authors interpreted their findings as being inconsistent with the free radical hypothesis of barbiturate action.

The major limitations of the above study, however, are that the nature of the reactive species responsible for initiating lipid peroxidation is uncertain and, more importantly, the extent to which this in vitro system mimics these conditions promoting ischaemic brain injury in vivo is unknown. It therefore seemed premature to dismiss the free radical scavenging theory of barbiturate protection until more specific information was obtained concerning the ability of barbiturates to interact with the various reactive oxygen species implicated in cellular injury in vivo. Such, then, was our objective in the present investigation.

Singlet oxygen is a highly reactive form of molecular oxygen which may be formed from the spontaneous dismutation of superoxide radicals, ${ }^{37}$ as a product of the interaction of hydrogen peroxide and superoxide radicals (the Haber-Weiss reaction) $)^{23}$ or from the action of light in the presence of certain naturally occurring pigments (such as the porphyrins) or photosensitizing dyes (such as Rose-Bengal). ${ }^{20}$ Singlet oxygen has been implicated in the process of prostaglandin synthesis ${ }^{38}$ and the ability of indomethacin to offer protection against concussive injury to the brain in the cat, may relate to the singlet oxygen-scavenging properties of this prostaglandin synthetase inhibitor. ${ }^{21}$ We have found phenobarbitone and pentobarbitone, even at concentrations considerably greater than those relevant to clinical anaesthesia, ${ }^{39}$ to be devoid of singlet oxygen scavenging properties, as apparent from their lack of effect on Rose Bengal photolytic damage to erythrocyte membrane protein and phospholipid components (Figure 1). On the other hand, thiopentone ( $1 \mathrm{mM})$, propranolol (1 mM) and chlorpromazine (0.1 $\mathrm{mM}$ ) each caused approximately 60 per cent protection against the elevation in malondialdehyde levels in erythrocyte membranes following Rose Bengal-sensitized photolysis (unpublished observations). These observations and the aforementioned results of Smith et al., ${ }^{36}$ who demonstrated protective effects of thiopentone and chlorpromazine against lipid peroxidative damage in brain homogenates, suggested that, while the susceptibility of membranes to radical attack in vitro may be effectively reduced by lipophilic substances with membrane stabilizing activity, pentobarbitone and phenobarbitone are relatively ineffective in this regard so that their protective actions in vivo are not likely to involve this mechanism. Further, the experiments depicted in Figure 2 indicate that the barbiturates can neither directly scavenge superoxide anions me- 
diating cytochrome $\mathrm{c}$ reduction nor interfere with the formation of these radicals during the oxidation of xanthine by xanthine oxidase.

The greatest effects of the barbiturates in the present study were exerted against hydrogen peroxide-induced oxidative damage in intact erythrocytes (Figure 3 ) at concentrations below and above $10^{-3} \mathrm{M}$, the level of phenobarbitone believed to be achieved in brain tissue during anaesthesia. ${ }^{39}$ Experiments with specific oxygen radical trappers (including the specific hydroxyl trapper formate) suggested a minor role of hydroxyl radicals in this system but the additive (and hence independent) protective effects of pentobarbitone and formate were an indirect indication that the barbiturates are not effective scavengers of these highly reactive and potentially damaging radical species. Rather, a major action of the barbiturates may involve the stabilization of haeme-coordinated ferrous ion against oxidative transformation, thereby minimizing its role in initiating and potentiating the free radical processes involved in the peroxidative destruction of cellular membrane lipids. ${ }^{24}$ Thus, the oxidation by sodium nitrite of red cell haemoglobin to methaemoglobin potentiates oxidative damage and appreciably decreases the protective actions of the barbiturates while leaving those due to direct membrane stabilization by propranolol unaltered (Figure 5). Direct evidence for the ability of various barbiturate analogues to prevent the peroxide-induced conversion of haemoglobin to methaemoglobin is presented in Figure 6. Methaemoglobin and hydrogen peroxide are known to form a reactive complex which is able, for example, to oxidize phenols to free radical intermediates ${ }^{40}$ and the complex has been implicated in the red cell damage caused by activated neutrophils. ${ }^{41}$ More generally, iron-coordinated complexes arising from extravasated blood, disrupted mitochondrial cytochrome components, or other sources may play an important role in the initiation of free radical-mediated processes responsible for tissue ischaemic or hypoxic injury. Our results suggest, therefore, that the barbiturates may act to diminish the effectiveness of ironcoordination complexes as catalysts for these processes and thereby reduce the extent of injury in tissues subjected to hypoxia or ischaemia.

\section{ACKNOWLEDGEMENT}

This work was supported by a grant from the
British Columbia Health Care Research Foundation.

\section{REFERENCES}

1. Arnfred, I. \& Secher, O. Anoxia and barbiturates. Arch. Int. Pharmacodyn. Ther. 139: 6774 (1962).

2. Michenfelder, J.D., Milde, J.H. \& Sundt, T.M. Cerebral protection by barbiturate anesthesia. Arch. Neurol. 33: 345-350 (1976).

3. SMITH, A.L., Hoff, J.T., Nielsen, S.L. \& LARSON, C.P. Barbiturate protection in acute focal cerebral ischemia. Stroke 5: 1-7 (1974).

4. Bleyaert, A.L., Nemoto, E.M. \& Safar, P. Thiopental amelioration of brain damage after global ischemia in monkeys. Anesthesiol. 49: 390-398, 1978.

5. RockofF, M.A., Marshall, L.F. \& Shapiro, H.M. High dose barbiturate therapy in humans: a clinical review of 60 patients. Ann. Neurol. 6 : 194-199 (1979).

6. Lawner, P., Laurent, J., Simeone, F., Fink, E. \& RUBIN, E. Attenuation of ischemic brain edema by pentobarbital after carotid ligation in the gerbil. Stroke 10:644-647 (1979).

7. SAFAR, P. Amelioration of post-ischemic brain damage with barbiturates. Stroke 11: 565-568 (1980).

8. Kofke, W.A., Nemoto, E.M., HossmanN, K.-A., TAYlor, F. Kessler, P.D. \& STEZOSKI, S.W. Brain blood flow and metabolism after global ischaemia and post-insult thiopental therapy in monkeys. Stroke 10: 554-560 (1979).

9. Demopoulos, H.B., Flam, E., Seligman, M.L., Poser, R., Pietronigro, D. \& RansoHOFF, J. In Oxygen and Physiological Function, F.F. Jobsis and P.I.L. Dallas (eds.), pp. 491508 (1977).

10. ReHNCRoNA, S., SMITH, D.S., Axesson, B. Westerberg, E. \& SiesJo, B.K. Peroxidative changes in brain cortical fatty acids and phospholipids as characterized during $\mathrm{Fe}^{+2}$ and ascorbic acid stimulated lipid peroxidation in vitro. J. Neurochem. 34: 1630-1638 (1980).

11. FRIDovich, I. Superoxide dismutase. Ann. Rev. Biochem. 44: 147-159 (1975).

12. Flamm, E.S., Demopoulos, H.B., Selifman, M.L. \& RANsohofF, J. Possible molecular mechanisms of barbiturate-mediated protection in regional cerebral ischemia. Acta Neurol. Scand. (Suppl. 64) 56: 150-151 (1977).

13. Demopoulos, H.B., Flamm, E.S., Seligman, M.L., JORGENSEN, E. \& RANSOHOFF, J. AntioXidant effects of barbiturates in model membranes undergoing free radical damage. Acta Neurol. Scand. (Suppl. 64) 56: 152-153 (1977).

14. Roth, S. \& SeEman, P. All lipid-soluble anaesthetics protect red cells. Nature (New Biology) 231: 284-285 (1971).

15. STOCKs, J. \& Dormandy, T.L. The autoxidation of human red cell lipids induced by hydrogen peroxide. Brit. J. Haematol. 20:95-111 (1971).

16. Godin, D.V. \& SCHRIER, S.L. Mechanism of inactivation of erythrocyte membrane adenosine 
triphosphatase by carbodiimides. Biochem. 9: 4068-4077 (1970).

17. Godin, D.V., Bridges, M.A. \& Macleod, P.J.M. Chemical compositional studies of erythrocyte membranes in Duchenne muscular dystrophy. Res. Commun. Chem. Pathol. Pharmacol. 20:331-349 (1978).

18. Cohen, H.J., Chovaniec, M.E. \& Ellis, S.E. Chlorpromazine inhibition of granulocyte superoxide production. Blood 56: 23-29 (1980).

19. TOMada, A., Tsuj, A. \& Yoneyama, Y. Involvement of superoxide anion in the reaction mechanism of haemoglobin oxidation by nitrite. Biochem. J. 193: 169-179 (1981).

20. Goosey, J.D., Zigler, JR, J.S. \& Kinoshita, J.H. Cross-linking of lens crystallins in a photodynamic system: a process mediated by singlet oxygen. Science 208: 1278-1280 (1980).

21. Bodaness, T.S. \& Chan, P.C. Reaction of indomethacin with singlet molecular oxygen. Biochem. Pharmacol. 29: 1337-1340 (1980).

22. NOHL, H. \& JORDAN, W. The metabolic fate of mitochondrial hydrogen peroxide. Eur. J. Biochem. 11I: 203-210 (1980)

23. Deneke, S.M. \& Fanburg, B.L. Normobaric oxygen toxicity of the lung. New Engl. J. Med. 303: 76-86 (1980)

24. TAPPEL, A.L. In Autoxidation and antioxidants, W.O. Lundberg, (ed.), Interscience, Vol. 1, New York, pp. 325-366, (1961)

25. WEBB, J.L. In Enzyme and Metabolic Inhibitors, Vol. 1, Academic Press, New York and London, p. 508 (1963)

26. GODIN, D.V., NG, T. WAN, \& TUCHEK, J.M. Studies on the interaction of propranolol with erythrocyte membranes. Biochim. Biophys. Acta 436: 757-773 (1976).

27. Kassell, N.F., Hitchon, P.W., Gerk, M.K., SOKOLL, M.D. \& HILL, T.R. Influence of changes in arterial $\mathrm{pCo}_{2}$ on cerebral blood flow and metabolism during high dose barbiturate therapy in dogs. J. Neurosug. 54: 615-619 (1981).

28. Breivik, J., Safar, P., Sands, P., Gabritius, R., Lind, B., LuSt, P., Mullie, A., ORr, M., RENCK, H., \& SNYDER, J.V. Clinical feasibility trials of barbiturate therapy after cardiac arrest. Crit. Care Med. 6: 228-244 (1978).

29. Steen, P.A., Milde, J.H. \& Michenfelder, J.D. No barbiturate protection in a dog model of complete cerebral ischemia. Ann. Neurol. 5: 343-349 (1979).
30. SNyder, B.D., Ramirez-Lassepas, M., SuKhUM, P., Fryd, D. \& SUNG, J.H. Failure of thiopental to modify global anoxic injury. Stroke 10: 135-141 (1979).

31. Steen, P.A. Barbiturate protection against ischemic brain damage. Scand. J. Clin. Lab. Invest. 40: 205-207 (1980).

32. Corkill, G., Sivalingam, S., Reitan, J.A., GILROY, B.A. \& HELPHREY, M.G. Dose dependency of the post-insult protective effect of pentobarbital in the canine experimental stroke model. Stroke 9: 10-18 (1978).

33. AstruP, J. Barbiturate protection in focal cerebral ischemia. Scand. J. Clin. Lab. Invest. 40 201-203 (1980).

34. MCCORD, J.M, Free radicals and inflammation: protection of synovial fluid by superoxide dismutase. Science 185: 529-531 (1974).

35. COHEN, G. \& HEIKKILA, R.E. The generation of hydrogen peroxide, superoxide radical and hydroxyl radical by 6-hydroxydopamine, dialuric acid, and related cytotoxic agents. J. Biol. Chem. 249: 2447-2452 (1974).

36. Smith, D.S., Rehncrona, S. \& Siesjo, B.K Inhibitory effects of different barbiturates on lipid peroxidation in brain tissue in vitro: a comparison with the effects of promethazine and chlorpromazine. Anesthesiol. 53: 186-194 (1980).

37. KAHN, A.U. Singlet molecular oxygen from superoxide anion and sensitized fluorescence of organic molecules. Science 168: 476-477 (1970).

38. Wei, E.P., Kontos, H.A., Dietrick, W.D. PovLISHOCK, J.T. \& Elus, E.F. Inhibition by free radical scavengers and by cyclooxygenase inhibitors of pial arteriolar abnormalities from concussive brain injury in cats. Circ. Res. 48 : 95-103 (1981).

39. Mark, L.C. Burns, J.J., Brand, L. Campomanes, C.I., Trousof, N., PAPPER, E.M. \& BrodiE, B.B. The passage of thiobarbiturates and their oxygen analogues into brain. J. Pharmacol. Exp. Ther. 123: 70-73 (1958)

40. Shiga, T. \& Imaizumi, K. Generation of phenoxy radicals by methemoglobin-hydrogen peroxide studied by electron paramagnetic resonance. Arch. Biochim. Biophys. 154: 540-547 (1973).

41. WeIss, S.J. The role of superoxide in the destruction of erythrocyte targets by human neutrophils. J. Biol. Chem. 255: 9912-9917 (1980).

\section{RÉsumé}

Bien que la théorie fondamentale du dommage cérébral ischémique ne soit pas encore élucidée, on a postulé que l'excès de production de dérivés réactifs de l'axygène moleculaire (tels les radicaux hydroxyl, superoxyde et l'oxygène univalent) pouvait jouer un rôle important dans la génèse de la lésion hypoxique. Cette capacité pour certains barbituriques de modifier la nature et l'étendue du dommage causé à la membrane par certains radicaux générés in vitro dans des conditions expérimentales spécifiques a été étudiée directement sur un modèle de membrane de l'érythrocyte humain. Nos résultats montrent que les barbituriques n'exercent probablement pas leur effet protecteur par 
epuration de l'oxygène univalent et des radicaux hydroxyl et superoxyde. Le thiopentone qui est une substance fortement lipophile a la propriété de diminuer la susceptibilité de la membrane à la dégradation oxydative par action membranaire directe, comme les stabilisateurs amphipatiques tels le propranolol. Les barbituriques stabilisent la fraction hème de l'hémoglobine en empêchant sa conversion en methémoglobine en présence de péroxyde d'hydrogène. Il est postulé qu'un facteur important de l'activité barbiturique dans la diminution de la lésion ischémique consiste à stabiliser les complexes ferreux contrôlés par la production d'hème, empêchant ces substances toujours présentes d'initier et de potentialiser les processus médiés par l'intervention des radicaux libres qu'on croit responsables de la production de la lésion. 